\title{
The COP1 E3-ligase interacts with FIP200, a key regulator of mammalian autophagy
}

\author{
Saori Kobayashi, Noriko Yoneda-Kato, Nagisa Itahara, Akihiro Yoshida and Jun-ya Kato*
}

\begin{abstract}
Background: The ubiquitin ligase COP1, COnstitutively Photomorphogenic 1, functions in many biological responses in mammalian cells, but its downstream pathway remains unclear.

Results: Here, we identified FIP200, a key regulator of mammalian autophagy, as a novel COP1-interacting protein by yeast two-hybrid screening. The interaction was confirmed by a GST-pulldown assay. Split-GFP analysis revealed that interaction between COP1 and FIP200 predominantly occurred in the cytoplasm and was enhanced in cells treated with UV irradiation. Different forms of FIP200 protein were expressed in cultured mammalian cells, and ectopic expression of COP1 reduced one of such forms.
\end{abstract}

Conclusions: These data suggest that COP1 modulates FIP200-associated activities, which may contribute to a variety of cellular functions that COP1 is involved in.

Keywords: COP1, FIP200(RB1CC1), UV, Autophagy

\section{Background}

COP1, COnstitutively Photomorphogenic 1 , is the ubiquitin ligase containing RING-finger, Coiled-coil and WD40 domains [1,2], and well conserved from plants to animals [2]. In plants, COP1 was identified as one of the COP proteins that act as a repressor of photomorphogenesis [1], and functions downstream of the COP9 signalosome complex [1-3] as a component of a multimeric E3 ubiquitin ligase complex that includes Cullin 4 (CUL4), Damaged DNA-Binding Protein 1 (DDB1), RING-Box 1 (RBX1), and Suppressor of Phya (SPA) proteins [4]. In response to multiple plant photoreceptors, the COP1-CUL4-DDB1RBX1-SPA complex controls many light-regulated transcription factors $[2,5]$.

In contrast to its specific role in plants, mammalian COP1 is involved in many biological responses such as tumorigenesis [6-9], DNA damage response [10,11], lipid metabolism [12], and gluconeogenesis [13] by targeting different substrates for degradation, which include p53 [6], c-Jun [8,14], Ets1/2 [9], TRB3 [12], and TORC2 [13]. Particularly, in a DNA-damage responsive pathway, COP1 functions downstream of ATM/ATR kinases by direct phosphorylation $[10,11]$, but the precise mechanism

\footnotetext{
* Correspondence: jkata@bs.naist.jp

Graduate School of Biological Sciences, Nara Institute of Science and Technology, Nara, Japan
}

remains to be determined. Considering a wide range of COP1 action in various biological responses, components and pathways downstream of COP1 are not fully understood yet.

To better understand the COP1-signaling pathway, we searched for novel COP1-interacting proteins by yeast two-hybrid screening and identified FIP200 as one such candidate. FIP200 (also known as RB1-inducible CoiledCoil 1, RB1CC1) was first reported as a regulator of the retinoblastoma (RB) protein [15], identified as a tumor suppressor in human breast cancer [16,17], and recently rediscovered as a mammalian counterpart of Atg17 in the yeast Atg1-Atg13-Atg17 complex [18]. The mammalian ULK1(Atg1)-Atg13-FIP200(Atg17) complex functions downstream of mTOR, and, together with the Beclin 1-Vps34 kinase pathway and the Atg5-Atg12 and LC3 conjugation systems, plays a key role in the induction of autophagy, an intracellular lysosomal degradation system for cytoplasmic proteins and organelles [19-23].

In this study, we investigated the interaction between COP1 and FIP200 by the yeast two-hybrid assay, the GST-pulldown assay, and the Split-GFP assay. Proliferating mammalian cells expressed several different forms of FIP200 protein, and one of them was downregulated by the ectopic overexpression of COP1 protein, suggesting that COP1 modulates FIP200-associated biological 
activities in a certain occasion, which may contribute to the complexity of the COP1-associated function.

\section{Results}

\section{Identification of FIP200 as an interactor with COP1}

To explore the novel signaling pathway mediated by COP1, we sought a candidate for interactors with COP1 by yeast two-hybrid screening of the human K562 erythroleukemia cDNA library. Out of $1.6 \times 10^{6}$ transformants, we chose 13 potential clones that repeatedly exhibited positive signals. These clones contained part of two independent cDNAs, one for Jun D and one for FIP200 [24]/RB1-inducible Coiled-Coil 1 [15] (RB1CC1). The presence of the former cDNA was anticipated given that c-Jun is a substrate of COP1 $[14,25]$ and that JunD is highly homologous to c-Jun, both of which belong to the same family of AP1 transcription factors. The latter component, FIP200, also termed RB1CC1, was originally shown to control retinoblastoma protein [15] and functions as a tumor suppressor in human breast cancer [16]. FIP200 was recently rediscovered as a component of the mammalian ULK1 (Atg1)Atg13-FIP200 (Atg17) complex and plays an important role in the induction of autophagy [18]. Therefore, we decided to investigate the COP1-FIP200 interaction and the role of COP1 in terms of UV response and induction of autophagy.

A yeast two-hybrid analysis using deletion mutants of COP1 (Figure 1A) indicated that the RING domain at the N-terminus of COP1 [6], but not the WD40 domain, is required for interaction with FIP200, showing a clear difference from JunD, which interacted with the WD40 domain as is the case with most substrates for ubiquitin ligases containing the WD40 motif [2]. In vitro binding assays using GST-fused FIP200 protein (Figure 1B) and cell lysate containing the ectopically expressed HAtagged COP1 (wild type and a mutant lacking the WD40 domain) showed that COP1 and FIP200 interacted in vitro (Figure 1B).

\section{Different forms of FIP200 protein were expressed in cultured mammalian cells}

To analyze the function of FIP200 in mammalian cells, we raised a rabbit polyclonal antibody to FIP200 using a polypeptide corresponding to the region isolated by the yeast two-hybrid screening, which specifically reacted with endogenous FIP200 as well as ectopically-expressed FIP200 protein by Wester blotting (Figure 2A). In the lysate isolated from proliferating mammalian cells, our antibody recognized two forms of FIP200 (Figure 2B),

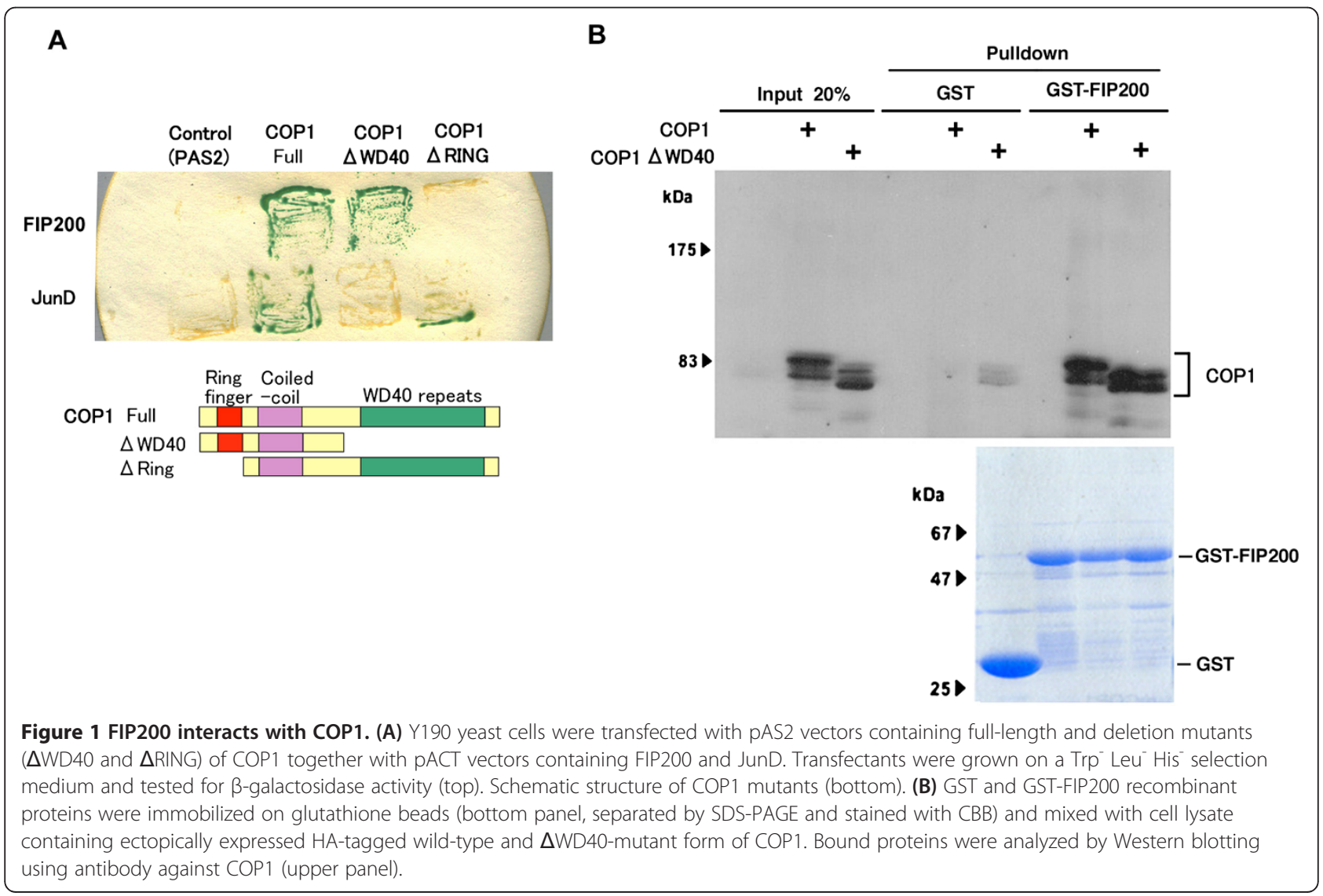




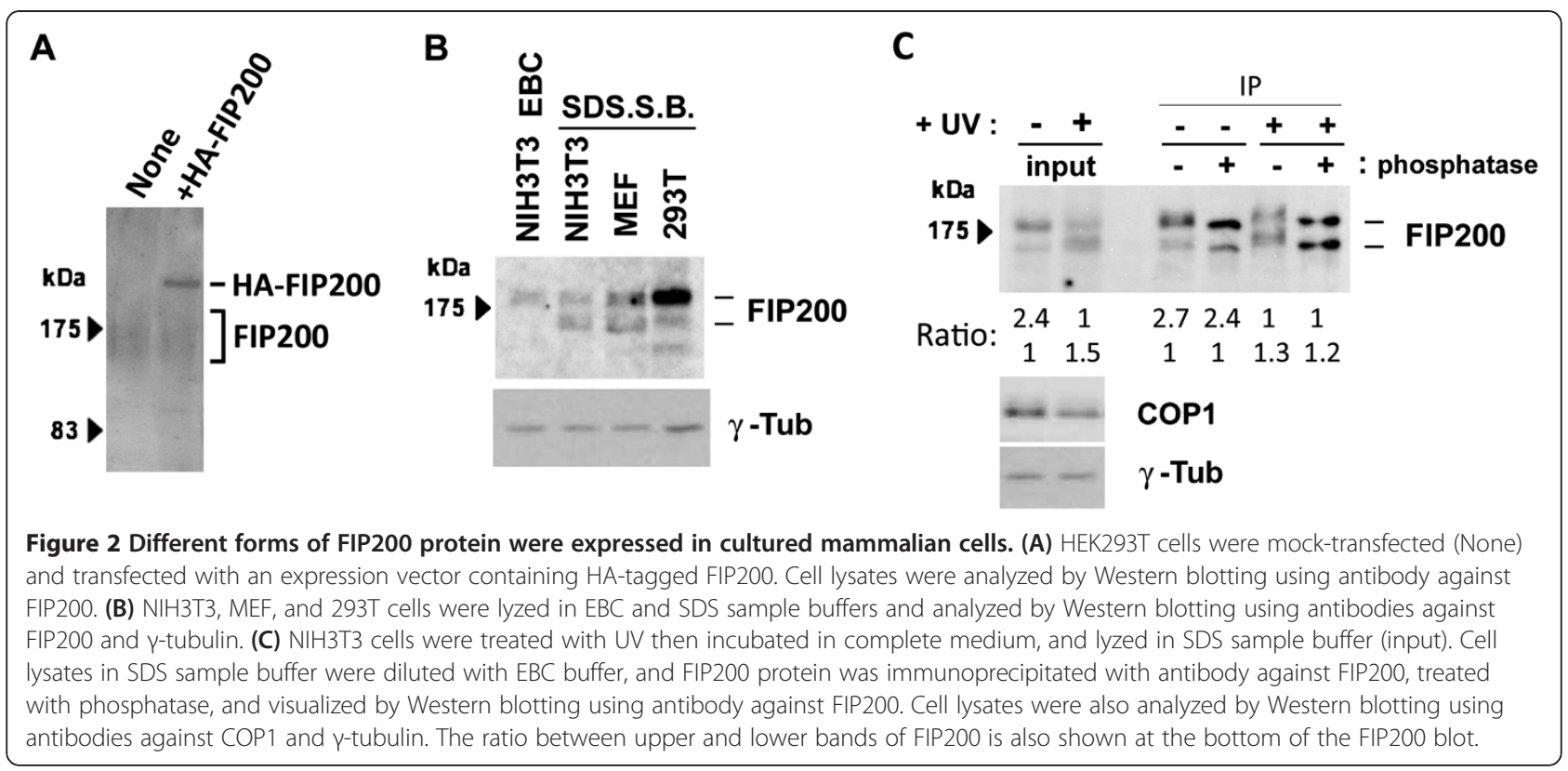

the slower migrating form being more readily extracted from the cells (EBC buffer containing $0.5 \%$ NP40 versus SDS sample buffer containing 1\% SDS). Because we have previously showed that COP1 is involved in cellular response mediated by UV stimulation [11], we examined whether UV might affect FIP200. Interestingly, UV stimulation altered the ratio between these two forms (Figure 2C); proliferating cells contained the slower migrating form more, while UV treatment decreased the expression of the slower migrating form and, instead, increased that of the faster migrating form (the level of COP1 declined after UV stimulation as previously reported [11]).

FIP200 is known to be modified by phosphorylation [26], which often affects mobility in SDS-PAGE. To test this possibility, we extracted the protein from cells treated with UV and un-treated cells in an SDS sample buffer, isolated FIP200 by immunoprecipitation, and treated it with phosphatase in vitro. The result (Figure 2C) showed that the difference in mobility was not due to the level of phosphorylation although both forms were phosphorylated. Currently, we do not know the exact molecular identity of these two variants, which might be generated by alternative splicing or other post-translational modifications.

\section{FIP200 interacts with COP1 in the cytoplasm of proliferating cells in response to UV stimulation}

We have so far not been successful in detecting the COP1-FIP200 complex in cell lysate by immunoprecipitation/immunoblotting. One possible explanation for this is that our antibody does not recognize the complex.
Another possibility is that the COP1-FIP200 complex may not be efficiently eluted from the cells in a buffer suitable for immunoprecipitation. In fact, we identified different forms of FIP200 by Western blotting possibly due to alternative splicing [16] and one of them was not efficiently extracted in a buffer for immunoprecipitation (Figure 2B).

To overcome these problems and to further investigate the interaction between COP1 and FIP200 in vivo, we performed a Split-GFP analysis [27], in which GFP (YFP) was split into two domains, N-terminal (YN) and Cterminal (YC), and fused to two molecules (COP1 and FIP200 in this case), respectively (Figure 3A). If these two molecules interact with each other in the cell, the GFP (YFP) signal will be restored. In transfected cells, COP1-YN, COP1-YC (both wild-type and mutant forms) and FIP200-YN together with YC and YN did not generate any significant signals above the background level, but we detected the GFP signal in the cells co-transfected with both wild-type COP1-YC and FIP200-YN after UV exposure (Figure 3B, C). The restored signal was predominantly in the cytoplasm (mostly perinuclear) with some in the nucleus too. We also detected interaction between COP1-YN and COP1-YC as a control. In this case, the signal was both in the nucleus and in the cytoplasm (Figure 3B). Quantification by flow cytometric analysis showed that the COP1-COP1 interaction was constitutive, whereas the COP1-FIP200 interaction was inducible in response to UV treatment (Figure 3C). Importantly, interaction was diminished when we used a COP1 mutant (SA), which contains a serine to alanine substitution at the conserved ATM/ATR phosphorylation site at the 389th 


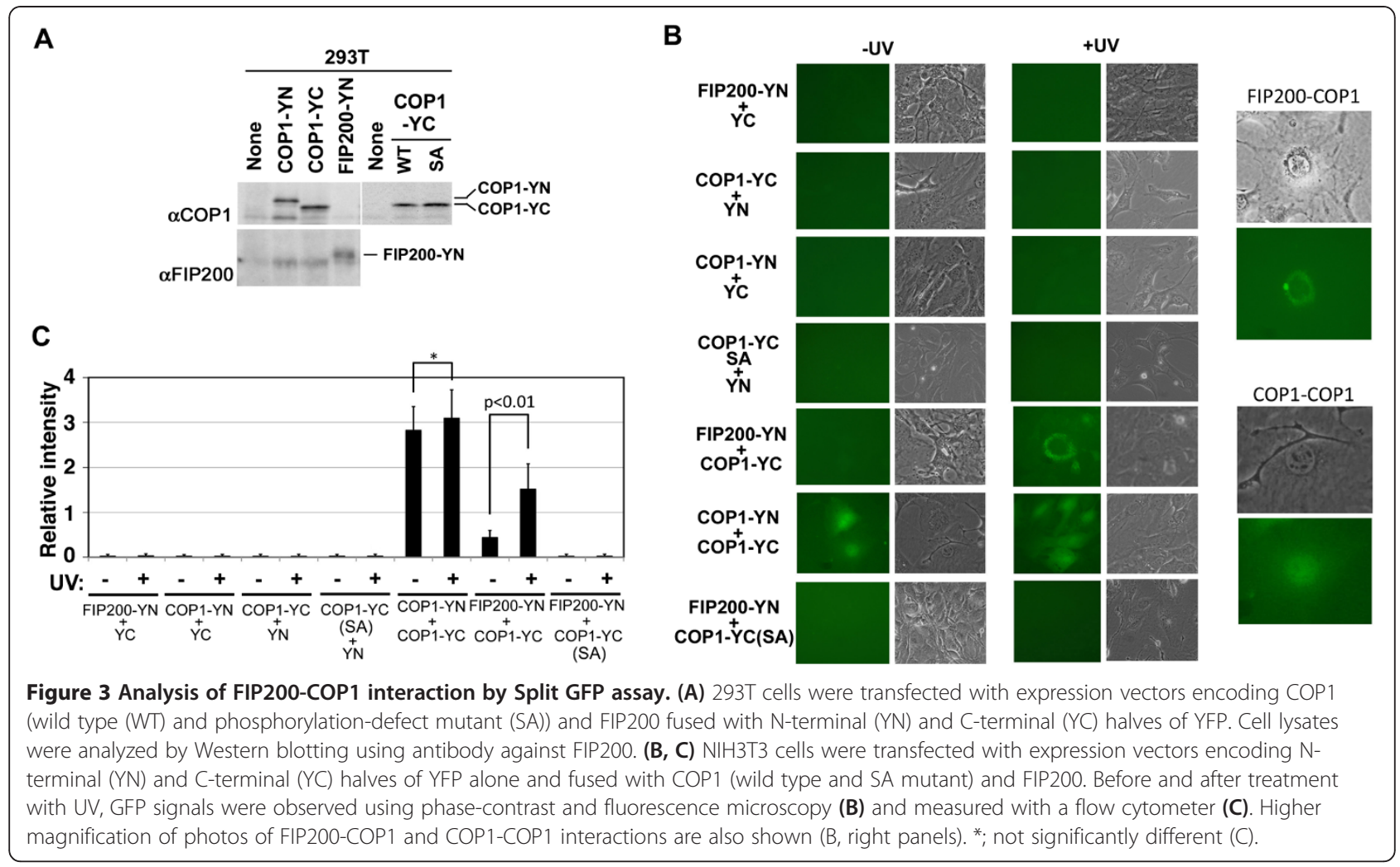

codon [10] (Figure 3B, C), suggesting that UV-mediated phosphorylation of COP1 is required for the efficient formation of a complex between COP1 and FIP200. Taken together, while COP1 stably forms a multimeric complex in the cell, its binding to FIP200 in the cytoplasm is enhanced by UV stimulation.
Ectopic expression of COP1 reduced the expression of a certain form of FIP200 protein and exhibited tumorigenisity in response to UV

To examine the effect of COP1 on FIP200, we ectopically expressed GFP-tagged COP1 in NIH3T3 (NIH/ GFP-COP1) cells. Figure 4A shows that the level of

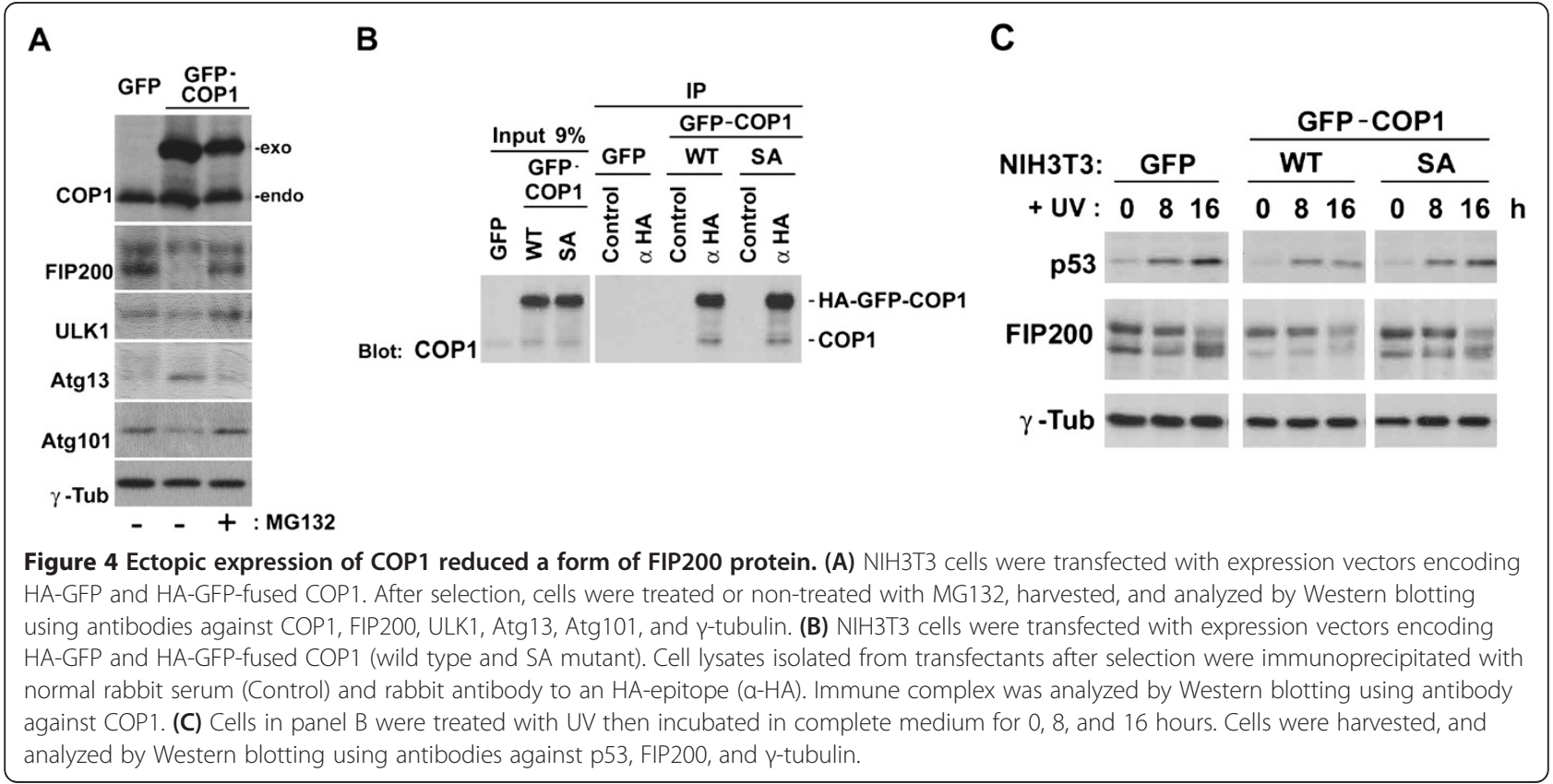


ectopic expression was approximately the same as that of the endogenous protein. Interestingly, the fastermigrating form of FIP200 was downregulated in NIH/ GFP-COP1 cells compared to that of the control (NIH/ GFP) cells transfected with the control GFP-vector, whereas the slower-migrating form remained the same. Because it is known that FIP200 forms a complex with ULK1, Atg13, and Atg101 to function downstream of mTOR to induce autophagy $[18,28]$, we investigated their expression. Figure 4A shows that ectopic expression of COP1 affected differently; ULK1 was almost unaffected, Atg13 was upregulated and Atg101 was slightly downregulated. We did not detect any direct binding of COP1 with ULK1, Atg13, and Atg101 (negative data not shown), suggesting that COP1 affects these components through interaction with FIP200. Interestingly, treatment of cells with an inhibitor to proteasome, MG132, reversed the effect of COP1 overexpression. When we investigated autophagy in these cells, however, autophagy was fully induced in response to amino acid starvation (negative data not shown). COP1 may affect other activities associated with FIP200.

Because interaction between COP1 and FIP200 was enhanced by UV stimulation and SA mutation diminished the interaction, we ectopically expressed wild type and SA mutant form of COP1 in NIH3T3 cells, and examined the effect of UV on FIP200. Figure 4B, left panel shows that both wild type and SA mutant COP1 were successfully overexpressed. Immunoprecipitation of the HA-tagged exogenous COP1 protein with the antibody to the HA epitope brought down the endogenous COP1 protein (Figure $4 \mathrm{~B}$, right panel), indicating that COP1 formed a dimer or a larger multimeric complex, which was expected from the split-GFP analysis (see above, Figure 3). The SA mutant retained the ability to interact with the endogenous COP1. Upon stimulation with UV (Figure 4C), the slower migrating form of FIP200 decreased and the faster migrating form increased in control cells. Overexpression of wild type COP1 reduced the level of faster migrating form at time 0 and blocked its induction by UV stimulation, whereas overexpression of SA mutant did not affect the band shift of FIP200 upon UV stimulation.

FIP200 was identified as a tumor suppressor [16,17]. If COP1 negatively regulates FIP200, one might expect that COP1 act as an oncogene. In addition, COP1 responds to UV stimulation and becomes a substrate of ATM/ ATR kinases [10,11]. We, therefore, tested whether the overexpression of COP1 facilitates cellular transformation in response to UV irradiation. We treated NIH3T3 mouse fibroblasts expressing COP1 with UV, let them recover for passaging, and subcutaneously injected them into NOD-SCID mice (Figure 5). Ectopic expression of the COP1 protein itself was not tumorigenic because no

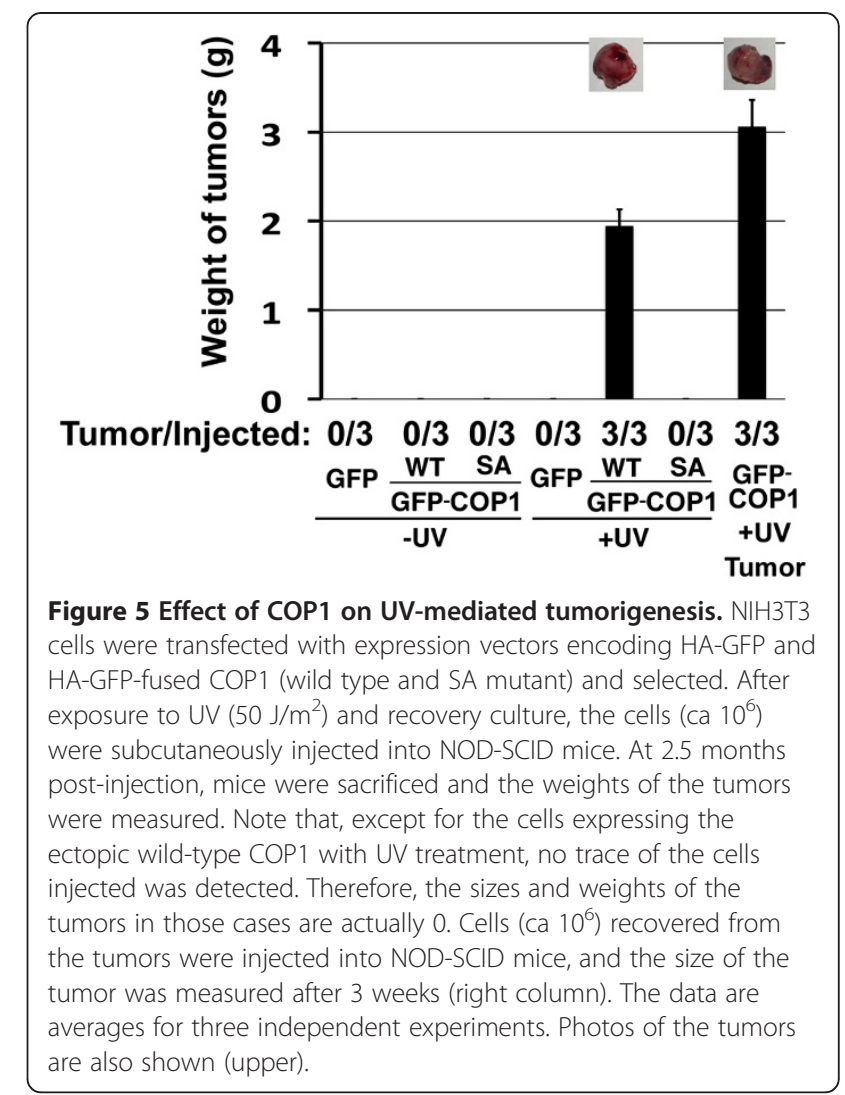

trace of cells was detected 2 months after injection. However, after treatment with UV and successive passages in a recovery culture, cells ectopically expressing COP1 formed a tumor of significant size in mice. Importantly, cells transfected with SA mutant of COP1, which did not interact with FIP200 (Figure 3B, C), failed to form tumors even after UV stimulation, suggesting that COP1 requires interaction with FIP200 to exhibit its oncogenic properties. We currently do not know the physiological significance of the impact of COP1 overexpression on autophagy. However, considering the differential effect on the expression of the components of the FIP200 complex and the FIP200 subtypes and that tumorigenic function of COP1 requires interaction with FIP200, it is feasible to say that COP1 may regulate biological activities associated with FIP200 in a certain occasion.

\section{Discussion}

As distinct from its plant counterpart [1], mammalian COP1 is involved in many biological occasions [2]. Multi-functionality of COP1 partly stems from its variety of substrates and various adaptor or accessory proteins to interact with. Although several proteins have been identified as the target of COP1 $[6,8,9,12-14]$, it is reasonable to speculate that more substrates and downstream pathways are yet to be found. Our findings imply 
that autophagy may situate downstream of the signaling pathway mediated by COP1, which may partly explain the multifunction of COP1 because autophagy is reported to be involved in many biological occasions [20,21].

By yeast-two hybrid screening, we identified C-terminal polypeptide of FIP200 as the interactor of COP1, and raised antibody against this portion of the protein. Using this antibody, we detected at least two different forms of FIP200 in proliferating mammalian cells, both of which should, therefore, share the epitope in the C-terminus of FIP200. Currently, we do not know the identity of these two forms of FIP200 recognized by our antibody because phosphorylation (Figure 2) and ubiquitination (anti-ubiquitin antibody failed to recognize either form. negative data not shown) do not seem to account for the mobility difference of these two forms. It is feasible to suspect that alternative splicing generated these two forms, but the extensive RT-PCR analysis using a series of primers designed within different exons failed to identify the alternative transcripts (negative data not shown). Therefore we do not exclude the possibility that the faster-migrating form is the product of other post-translational modifications. Whatever the mechanism, it is important to emphasize that these two forms were extracted in different conditions and that only the fastermigrating form was downregulated by the ectopic expression of COP1, suggesting that they locate in different compartments within the cell and that one of the two is the possible target of COP1.

We do not yet know whether FIP200 is a substrate for the COP1 ligase. FIP200 bound to the RING domain, but not the WD40 domain, of COP1, which makes a clear difference from other substrates such as JunD. We, so far, did not see the ubiquitinated FIP200 protein in COP1-overexpressing cells. However, we did observe the downregulation of fastermigrating form of FIP200 in COP1-overexpressing cells in an MG132-sensitive manner, suggesting that COP1 somehow induced proteasome-mediated degradation of FIP200. At present, we do not exclude the possibility that COP1 altered the level of FIP200 expression through mechanisms other than direct ubiquitination. COP1 might affect alternative-splicing to affect the expression of fastermigrating form, which step is sensitive to the action of proteasome.

Cells with ectopic overexpression of COP1 still underwent autophagy in response to amino acid starvation even though the faster-migrating form of FIP200 was efficiently downregulated, and the expression of Atg13 and Atg101 was modulated (although slightly). It could be that the remaining components of the FIP200 complex were sufficient to the initiate autophagic program or alternative form of FIP200 may respond to different inducers of autophagy such as UV. To answer this question, molecular identification of two forms of FIP200 is the urgent matter. Knowing the difference between the two, we could compare the composition of the different complexes and examine the role of each form in response to various stimuli, and the potential functions associated with FIP200 in the cell cycle control [15], p53 regulation [17] and DNA damage repair [29] as well as autophagy [18].

We have tried to establish the in vitro ubiquitination assay for COP1 and FIP200 using recombinant proteins without success (negative data not shown). This could be due to the lack of the COP1-accessory proteins or, alternatively, COP1 may favor the FIP200-containing complex rather than a single polypeptide. In addition to the identity of FIP200 variants, an adaptor protein of COP1 specific to FIP200 will be required for establishment of the in vitro reconstitution system, which will give us many clues to biochemically understand the nature of COP1-associated activities in mammals.

\section{Methods}

\section{Yeast two-hybrid screening}

The entire coding sequence (full) and deletion mutants $(\triangle \mathrm{WD} 40$ and $\triangle \mathrm{RING}$,) of mouse COP1 were fused inframe to the GAL4 DNA-binding domain of the pAS2 vector [30]. The resulting 'bait' plasmid (pAS2-COP1) was used to screen pACT- human K562 erythroleukemia libraries (library size: $3 \times 10^{6}$, Clontech) by the yeast two-hybrid method in Y190 yeast cells [11,30,31].

\section{In vitro binding assay}

A cDNA fragment containing the C-terminal domain of FIP200 (amino acid residues 1357-1594) was inserted into the pGEX vector (Pharmacia) in-frame with Glutathione S-transferase (GST). Expression and purification of GST-fused proteins and the binding conditions were as described [11,32].

\section{Cell culture, transfection, retroviral infection, and treatment with UV}

NIH3T3 (Arf-null, p53-wild-type) mouse fibroblasts (provided by Drs C. J. Sherr and M. F. Roussel), mouse embryonic fibroblasts (MEFs), and 293T human embryonic kidney (HEK) cells were cultured, transfected via the calcium phosphate-DNA precipitation method [33], and infected with retroviral vectors as described $[11,32,34]$. For treatment with UV, cells were washed with PBS twice, exposed to UV light in a UV Crosslinker (UVP, Upland, CA) $\left(25\right.$ or $\left.50 \mathrm{~J} / \mathrm{m}^{2}\right)$, and incubated in a serum-containing complete medium. In some cases, cells were treated with 5 4M MG132 (Biomol, Plymouth Meeting, PA) before harvest.

\section{Plasmid construction}

The GFP-fused protein expression vector (pMSCVpuro-GFP), into which COP1 cDNAs were subcloned, 
was described previously [11]. COP1 mutants ( $\triangle \mathrm{WD} 40$, $\triangle$ RING and SA) $[6,10,14,35]$ were generated by PCR.

\section{Protein analyses}

Cell lysis, immunoprecipitation, sodium dodecyl sulfatepolyacrylamide gel electrophoresis (SDS-PAGE), and immunoblotting were performed as described [11,34]. Two types of lysis buffer used in this study were EBC buffer (50 mM Tris- $\mathrm{HCl}$ pH8.0, $120 \mathrm{mM} \mathrm{NaCl}, 1 \mathrm{mM}$ EDTA, and $0.5 \% \mathrm{NP} 40$ ) containing $2000 \mathrm{KIU} / \mathrm{ml}$ of aprotinin, $1 \mathrm{mM}$ PMSF, $0.1 \mathrm{mM} \mathrm{NaF}, 0.1 \mathrm{mM} \mathrm{Na} 3 \mathrm{VO} 4$, and $10 \mathrm{mM}$ $\beta$-glycerophosphate, and SDS-sample buffer $(40 \mathrm{mM}$ Tris-HCl, pH 6.8, 0.1 M DTT, 1\% SDS, 10\% glycerol, and 0.05\% Bromophenol Blue). In some cases, immunoprecipitated proteins were treated with phosphatase before immunoblotting [36]. A rabbit polyclonal antibody to an HA-epitope (HA.11) was obtained from Santa Cruz. A mouse monoclonal antibody to an HA-epitope (clone 12CA5) was purchased from Boehringer Mannheim. Rabbit polyclonal antibodies to ULK1 (A7481) and Atg13 (SAB4200100) were from Sigma. Rabbit polyclonal antibodies to LC3 (PM036) and p62 (PM045) were acquired from Medical \& Biological Laboratories (MBL). Rabbit polyclonal antibodies to FIP200, p53, and COP1 were generated using bacterially produced polypeptides in our laboratory. A rabbit polyclonal antibody to Atg101 was provided by Dr. Noboru Mizushima.

\section{Split GFP assay}

GFP (YFP) was split into two domains, N-terminal (YN: amino acids 1-154) and C-terminal (YC: amino acids 155-238). Each domain was fused to two molecules (full-length COP1 and FIP200 in this case), and transfected into cells as described above. GFP signals were observed using phase-contrast or fluorescence microscopy and measured with a flow cytometer. A human cDNA clone containing entire coding sequence of FIP200 was obtained from Kazasa DNA Research Institute (clone niumber: KIAA0203).

\section{Tumorigenicity assay}

Cells $\left(\mathrm{ca} 10^{6}\right)$ were subcutaneously injected into NODSCID mice. After 3 weeks or 2.5 months, mice were sacrificed and the size of the tumor was measured.

\section{Conclusion}

In this study, we found the interaction between FIP200 and COP1. Ectopic expression of COP1 reduced one of the different forms of FIP200, suggesting that COP1 modulates FIP200-associated activities, which may contribute to a variety of cellular functions that COP1 is involved in.

\section{Authors' contributions}

SK carried out the molecular biological studies. NI carried out the molecular cellular studies. AY performed the cellular analysis. NY-K and J-yK conceived of the study and participated in its design and coordination and drafted the manuscript. All authors read and approved the final manuscript.

\section{Acknowledgements}

We thank Drs. C. J. Sherr and M. F. Roussel for the NIH3T3 cell line; Dr. N. Mizushima for the antibody to Atg101; Ms. I. Nakamae for excellent technical assistance. This work was partly supported by Grants-in-Aid for Scientific Research and for Cancer Research from the Ministry of Education, Science, and Culture of Japan. There is no conflict of interest.

Received: 25 May 2012 Accepted: 2 January 2013

Published: 6 January 2013

\section{References}

1. Osterlund MT, Ang LH, Deng XW: The role of COP1 in repression of Arabidopsis photomorphogenic development. Trends Cell Biol 1999, 9(3):113-118.

2. Yi C, Li S, Wang J, Wei N, Deng XW: Affinity purification reveals the association of WD40 protein constitutive photomorphogenic 1 with the hetero-oligomeric TCP-1 chaperonin complex in mammalian cells. Int J Biochem Cell Biol 2006, 38(7):1076-1083.

3. Kato JY, Yoneda-Kato N: Mammalian COP9 signalosome. Genes Cells 2009, 14(11):1209-1225.

4. Chen H, Huang X, Gusmaroli G, Terzaghi W, Lau OS, Yanagawa Y, Zhang Y, Li J, Lee JH, Zhu D, et al: Arabidopsis CULLIN4-damaged DNA binding protein 1 interacts with CONSTITUTIVELY PHOTOMORPHOGENIC1SUPPRESSOR OF PHYA complexes to regulate photomorphogenesis and flowering time. Plant Cell 2010, 22(1):108-123.

5. Favory JJ, Stec A, Gruber H, Rizzini L, Oravecz A, Funk M, Albert A, Cloix C, Jenkins Gl, Oakeley EJ, et al: Interaction of COP1 and UVR8 regulates UVB-induced photomorphogenesis and stress acclimation in Arabidopsis. EMBO J 2009, 28(5):591-601.

6. Dornan D, Wertz I, Shimizu H, Arnott D, Frantz GD, Dowd P, O'Rourke K, Koeppen H, Dixit VM: The ubiquitin ligase COP1 is a critical negative regulator of p53. Nature 2004, 429(6987):86-92.

7. Dornan D, Bheddah S, Newton K, Ince W, Frantz GD, Dowd P, Koeppen H, Dixit VM, French DM: COP1, the negative regulator of $\mathrm{p} 53$, is overexpressed in breast and ovarian adenocarcinomas. Cancer Res 2004 64(20):7226-7230.

8. Migliorini D, Bogaerts S, Defever D, Vyas R, Denecker G, Radaelli E, Zwolinska A, Depaepe V, Hochepied T, Skarnes WC, et al: Cop1 constitutively regulates c-Jun protein stability and functions as a tumor suppressor in mice. J Clin Invest 2011, 121(4):1329-1343.

9. Vitari AC, Leong KG, Newton K, Yee C, O'Rourke K, Liu J, Phu L, Vij R, Ferrando R, Couto SS, et al: COP1 is a tumour suppressor that causes degradation of ETS transcription factors. Nature 2011, 474:403-406.

10. Dornan D, Shimizu H, Mah A, Dudhela T, Eby M, O'Rourke K, Seshagiri S, Dixit VM: ATM engages autodegradation of the E3 ubiquitin ligase COP1 after DNA damage. Science 2006, 313(5790):1122-1126.

11. Yoneda-Kato N, Tomoda K, Umehara M, Arata Y, Kato JY: Myeloid leukemia factor 1 regulates $\mathrm{p} 53$ by suppressing COP1 via COP9 signalosome subunit 3. EMBO J 2005, 24(9):1739-1749.

12. Qi L, Heredia JE, Altarejos JY, Screaton R, Goebel N, Niessen S, Macleod IX, Liew CW, Kulkarni RN, Bain J, et al: TRB3 links the E3 ubiquitin ligase COP1 to lipid metabolism. Science 2006, 312(5781):1763-1766.

13. Dentin R, Liu Y, Koo SH, Hedrick S, Vargas T, Heredia J, Yates J 3rd, Montminy M: Insulin modulates gluconeogenesis by inhibition of the coactivator TORC2. Nature 2007, 449(7160):366-369.

14. Wertz IE, O'Rourke KM, Zhang Z, Dornan D, Arnott D, Deshaies RJ, Dixit VM: Human De-etiolated-1 regulates c-Jun by assembling a CUL4A ubiquitin ligase. Science 2004, 303(5662):1371-1374.

15. Chano T, Ikegawa S, Kontani K, Okabe H, Baldini N, Saeki Y: Identification of RB1CC1, a novel human gene that can induce RB1 in various human cells. Oncogene 2002, 21(8):1295-1298.

16. Chano T, Kontani K, Teramoto K, Okabe H, Ikegawa S: Truncating mutations of RB1CC1 in human breast cancer. Nat Genet 2002, 31(3):285-288. 
17. Melkoumian ZK, Peng X, Gan B, Wu X, Guan JL: Mechanism of cell cycle regulation by FIP200 in human breast cancer cells. Cancer Res 2005, 65(15):6676-6684.

18. Hara T, Takamura A, Kishi C, lemura S, Natsume T, Guan JL, Mizushima N: FIP200, a ULK-interacting protein, is required for autophagosome formation in mammalian cells. J Cell Biol 2008, 181(3):497-510.

19. Mizushima N: Autophagy: process and function. Genes Dev 2007, 21(22):2861-2873.

20. Levine B, Kroemer G: Autophagy in the pathogenesis of disease. Cell 2008, 132(1):27-42.

21. Mizushima N, Levine B, Cuervo AM, Klionsky DJ: Autophagy fights disease through cellular self-digestion. Nature 2008, 451(7182):1069-1075.

22. Kroemer $G$, Marino $G$, Levine B: Autophagy and the integrated stress response. Mol Cell 2010, 40(2):280-293.

23. Mizushima N, Komatsu M: Autophagy: renovation of cells and tissues. Cell 2011, 147(4):728-741.

24. Gan B, Melkoumian ZK, Wu X, Guan KL, Guan JL: Identification of FIP200 interaction with the TSC1-TSC2 complex and its role in regulation of cell size control. J Cell Biol 2005, 170(3):379-389.

25. Bianchi E, Denti S, Catena R, Rossetti G, Polo S, Gasparian S, Putignano S, Rogge L, Pardi R: Characterization of human constitutive photomorphogenesis protein 1, a RING finger ubiquitin ligase that interacts with Jun transcription factors and modulates their transcriptional activity. J Biol Chem 2003, 278(22):19682-19690.

26. Mizushima N: The role of the Atg1/ULK1 complex in autophagy regulation. Curr Opin Cell Biol 2010, 22(2):132-139.

27. Hu CD, Chinenov Y, Kerppola TK: Visualization of interactions among bZIP and Rel family proteins in living cells using bimolecular fluorescence complementation. Mol Cell 2002, 9(4):789-798.

28. Hosokawa N, Sasaki T, lemura S, Natsume T, Hara T, Mizushima N: Atg101, a novel mammalian autophagy protein interacting with Atg13. Autophagy 2009, 5(7):973-979.

29. Bae H, Guan JL: Suppression of autophagy by FIP200 deletion impairs DNA damage repair and increases cell death upon treatments with anticancer agents. Mol Cancer Res 2011, 9(9):1232-1241.

30. Harper JW, Adami GR, Wei N, Keyomarsi K, Elledge SJ: The p21 Cdkinteracting protein Cip1 is a potent inhibitor of G1 cyclin-dependent kinases. Cell 1993, 75(4):805-816.

31. Durfee T, Becherer K, Chen PL, Yeh SH, Yang Y, Kilburn AE, Lee WH, Elledge SJ: The retinoblastoma protein associates with the protein phosphatase type 1 catalytic subunit. Genes Dev 1993, 7(4):555-569.

32. Tomoda K, Kubota Y, Arata Y, Mori S, Maeda M, Tanaka T, Yoshida M, Yoneda-Kato N, Kato JY: The cytoplasmic shuttling and subsequent degradation of p27Kip1 mediated by Jab1/CSN5 and the COP9 signalosome complex. J Biol Chem 2002, 277(3):2302-2310.

33. Chen C, Okayama H: High-efficiency transformation of mammalian cells by plasmid DNA. Mol Cell Biol 1987, 7(8):2745-2752.

34. Kato JY, Nakamae I, Tomoda K, Fukumoto A, Yoneda-Kato N: Preparation and characterization of monoclonal antibodies against mouse Jab1/ CSN5 protein. Hybridoma (Larchmt) 2006, 25(6):342-348.

35. Savio MG, Rotondo G, Maglie S, Rossetti G, Bender JR, Pardi R: COP1D, an alternatively spliced constitutive photomorphogenic-1 (COP1) product, stabilizes UV stress-induced c-Jun through inhibition of full-length COP1. Oncogene 2008, 27(17):2401-2411.

36. Kato J, Matsushime H, Hiebert SW, Ewen ME, Sherr CJ: Direct binding of cyclin $\mathrm{D}$ to the retinoblastoma gene product $(\mathrm{pRb})$ and $\mathrm{pRb}$ phosphorylation by the cyclin D-dependent kinase CDK4. Genes Dev 1993, 7(3):331-342

doi:10.1186/1471-2091-14-1

Cite this article as: Kobayashi et al:: The COP1 E3-ligase interacts with FIP200, a key regulator of mammalian autophagy. BMC Biochemistry 2013 $14: 1$

\section{Submit your next manuscript to BioMed Central and take full advantage of:}

- Convenient online submission

- Thorough peer review

- No space constraints or color figure charges

- Immediate publication on acceptance

- Inclusion in PubMed, CAS, Scopus and Google Scholar

- Research which is freely available for redistribution 